7-1-1993

\title{
Tribological Characteristics of Perfluoropolyether Liquid Lubricants Under Sliding Conditions in High Vacuum
}

\author{
Masabumi Masuko \\ William R. Jones Jr \\ Larry S. Helmick \\ Cedarville University, helmickl@cedarville.edu
}

Follow this and additional works at: https://digitalcommons.cedarville.edu/

science_and_mathematics_publications

Part of the Chemical Engineering Commons, and the Chemistry Commons

\section{Recommended Citation \\ Helmick, L. S. (1993). Tribological Characteristics of Perfluoropolyether Liquid Lubricants Under Sliding Conditions in High Vacuum. NASA Technical Memorandum (106257).}

This Technical Memorandum is brought to you for free and open access by DigitalCommons@Cedarville, a service of the Centennial Library. It has been accepted for inclusion in Science and Mathematics Faculty Publications by an authorized administrator of DigitalCommons@Cedarville. For more information, please contact digitalcommons@cedarville.edu. 


\section{Tribological Characteristics of Perfluoropolyether Liquid Lubricants Under Sliding Conditions in} High Vacuum

Masabumi Masuko

Tokyo Institute of Technology

Tokyo, Japan

and

William R. Jones, Jr. and Larry S. Helmick

Lewis Research Center

Cleveland, Ohio

Prepared for the

Eurotrib 1993

sponsored by the Hungarian Society of Mechanical Engineers

Budapest, Hungary, August 30-September 2, 1993

(NASA-TM-106257) TRIBOLOGICAL

N93-32352

CHARACTERISTICS OF

PERFLUOROPOLYETHER LIOUID

LUBRICANTS UNDER SLIDING CONDITIONS UnCIaS

N/SN

IN HIGH VACUUM (NASA) 7 p 


\title{
TRIBOLOGICAL CHARACTERISTICS OF PERFLUOROPOLYETHER LIQUID LUBRICANTS UNDER SLIDING CONDITIONS IN HIGH VACUUM
}

\author{
Masabumi Masuko \\ Tokyo Institute of Technology \\ Tokyo, Japan \\ and
}

\author{
William R. Jones, Jr. and Larry S. Helmick \\ National Aeronautics and Space Administration \\ Lewis Research Center \\ Cleveland, Ohio 44135
}

\section{SUMMARY}

Tribological characteristics of three PFPE's (Fomblin Z, Demnum and Krytox) were studied under high vacuum using a four-ball apparatus with $440 \mathrm{C}$ steel specimens. Fomblin $\mathrm{Z}$ and Demnum exhibited initial scuffing-like high friction whereas Krytox did not. Steady state friction with Fomblin $\mathrm{Z}$ was the lowest among the three oils and that with Demnum and Krytox were almost the same. The lowest wear rates in air was provided by Krytox regardless of load and low wear rates in vacuum at high load were achieved with Krytox and Demnum. Results are explained by reactivity and pressureviscosity characteristics of the oils.

\section{INTRODUCTION}

Perfluoropolyethers (PFPE's) have been used as lubricants for space applications for many years because of their wide liquid range, low volatility, high viscosity index, and chemical inertness. Most space mechanisms, where liquid lubrication is currently required, include bearings for actuators, gyroscopes, momentum wheels, scanning mirrors and filter wheels (1). In addition, other mechanisms such as gears or harmonic drives, where contact conditions are more severe than in rolling element bearings, also require liquid or grease lubrication.

Many PFPE stability studies, such as thermal (2), oxidative (3), and catalytic $(4,5)$ have been reported concerning PFPE degradation. Studies concerning the tribological behavior of PFPE's are less common $(6,7)$, particularly sliding experiments under high load in a vacuum environment (8).

Therefore, the objective of this study was to compare the ability of three commercially available PFPE lubricants to reduce wear/friction in the boundary regime using a newly designed vacuum four-ball tribometer. Conditions included: dry air and vacuum $\left(10^{-4}\right.$ to $\left.10^{-6} \mathrm{~Pa}\right)$ environments, loads of 200 and $600 \mathrm{~N}$, a rotational speed of $100 \mathrm{rpm}$, and room temperature $\left(\sim 23^{\circ} \mathrm{C}\right)$.

\section{EXPERIMENTAL--Vacuum Four-Ball Tribometer}

The apparatus has been previously described (9). The specimen configuration is the same as the standard four-ball apparatus. In this tribometer, $9.5 \mathrm{~mm}(3 / 8 \mathrm{in}$.) diameter 
bearing balls made of AISI $440 \mathrm{C}$ stainless steel were used as test specimens. The specimen stage is mounted in a vacuum chamber.

Tests were carried out under a constant sliding speed of $2.88 \times 10^{-2} \mathrm{~m} / \mathrm{s}(100 \mathrm{rpm})$ and two axial loads $(200 \mathrm{~N}$ and $600 \mathrm{~N})$. All tests were conducted at room temperature $\left(\sim 23^{\circ} \mathrm{C}\right)$. Vacuum tests were started after the pressure reached $10^{-5} \mathrm{~Pa}$ or less.

Measurement of Friction and Wear

Frictional force was recorded continuously. Wear scar diameters for the three stationary balls were measured with an optical microscope and then averaged. The microscope stage allowed for wear scar measurements without disassembling the balls from the cup. Therefore, the experiment could be continued using the same set of balls. Wear volume was calculated from the wear scar diameter. Wear on the rotating (upper) ball was not measured.

Test Lubricants

Three commercially available PFPE lubricants were studied (Demnum S100, Fomblin Z25 and Krytox 143AB). All have similar viscosities at room temperature. Other properties appear in Ref. 2.

\section{RESULTS--Comparison of Wear Rate}

Wear volume as a function of sliding distance appears in figure 1 . Wear volume increased almost linearly with sliding distance. This relationship was observed for all experiments. Therefore, wear rate, defined as the wear volume per unit sliding distance, $\mathrm{mm}^{3} / \mathrm{mm}$, was calculated from the slope of this relationship.

Wear rates are compared in figure 2. From the comparison of the wear rate at $200 \mathrm{~N}$, it can be seen that Krytox allows less wear than the other two PFPE oils, regardless of environment. In general, wear rates are higher in vacuum than in air. In particular, Fomblin $Z$ exhibited a very high wear rate in vacuum at $600 \mathrm{~N}$. Reproducibility of the Fomblin $Z$ results was poorer than the other two lubricants.

Comparison of Friction Coefficient

Friction coefficients were normally steady throughout the experiments, except for the initial region. Steady state friction coefficients obtained in vacuum are less than that in air ( 5 to $20 \%$ ), regardless of lubricant or load. Fomblin $\mathrm{Z}$ yields the lowest friction coefficient both in air (0.11) and in vacuum (0.10) under both loads, but variation of the friction coefficient in the steady state region, was greater than those obtained with the other two lubricants.

\section{High Initial Friction Coefficient}

At $200 \mathrm{~N}$, none of the lubricants exhibited high transient initial friction coefficients. At $600 \mathrm{~N}$, initial high friction was not observed for Krytox in either environment, whereas Demnum and Fomblin $Z$ exhibited transient initial high friction regions. 
However, their magnitudes were different (i.e., higher with Demnum (0.16) than with Fomblin $\mathrm{Z}(0.13)$ ), whereas the durations were similar ( $<3$ minutes).

\section{DISCUSSION}

Characteristic features of the results in vacuum are as follows: Fomblin $\mathbf{Z}$ yielded the lowest friction but the highest wear rate, among the three lubricants, particularly at $600 \mathrm{~N}$. Both Fomblin Z and Demnum showed scuffing-like behavior (transient high friction) düring the initial stage of the experiments, but the friction coefficient in this stage was greater with Demnum than with Fomblin Z. Krytox did not exhibit any initial high friction although steady state friction was almost equal to that of Demnum.

It has been suggested that Fomblin $\mathrm{Z}$ easily decomposes thermally or catalytically forming reactive species. The stability of Fomblin $Z$ in the presence of a catalytic surface is the lowest among the three PFPE's of this study (4). This instability occurs because of the presence of formal groups $-\left(\mathrm{OCF}_{2} \mathrm{O}\right)$-. Fomblin $\mathrm{Z}$ is much more reactive than either Krytox or Demnum. In addition, it has been also shown that PFPE oils form metallic fluorides, both thermally and tribologically (6).

The pressure-viscosity coefficient $(\alpha)$ of Krytox, which is indicative of the capability of elastohydrodynamic (EHL) film formation, is the greatest among the three test fluids (about $4.5 \times 10^{-8} \mathrm{~Pa}^{-1}$ at $38^{\circ} \mathrm{C}$ ) whereas that of Fomblin $\mathrm{Z}$ is about $1.5 \times 10^{-8} \mathrm{~Pa}^{-1}$. Values for Demnum are intermediate $\left(\sim 2.6 \times 10^{-8} \mathrm{~Pa}^{-1}\right)$.

By considering both reactivity and pressure-viscosity behavior, the tribological characteristics of the fluids can be explained as follows: A low steady state friction coefficient with an accompanying high wear rate which was obtained with Fomblin $Z$ is similar to the behavior of highly reactive additives (such as EP agents). Since Fomblin $\mathrm{Z}$ is very reactive and forms metal fluorides, as discussed earlier, it is reasonable to conclude that the tribological characteristics of Fomblin $Z$ is similar to that of EP additives (i.e., chemical or corrosive wear).

This can also explain the initial high friction obtained with Demnum and Fomblin $Z$. Since the initial contact pressure is very high, (mean Hertzian stress is $2.2 \mathrm{GPa}(200 \mathrm{~N})$ and $3.17 \mathrm{GPa}(600 \mathrm{~N}))$, local scuffing can occur. If the lubricant can react with the surface to minimize scuffing by forming EP layer-like surface films, the initial scuffing (high friction) can be effectively suppressed. Therefore, it is plausible that the less reactive Demnum would show higher initial transient friction than Fomblin $\mathbf{Z}$.

Lubricant reactivity cannot explain the lack of initial high friction with Krytox, but EHL effects may come into play. EHL film thickness can be calculated with following equation:

$$
\frac{h}{R^{\prime}}=k\left(\frac{U \eta_{0}}{E^{\prime} R^{\prime}}\right)^{a}\left(\alpha E^{\prime}\right)^{b}\left(\frac{W}{E^{\prime} R^{\prime}}\right)^{c}
$$

EHL minimum film thicknesses $\left(h_{\min }\right)$ can be calculated for the various lubricants based on initial contact conditions (i.e., before any wear or contact heating occurs). Fomblin $\mathrm{Z}$ yields the following results: $0.025 \mu \mathrm{m}(200 \mathrm{~N})$ and $0.023 \mu \mathrm{m}(600 \mathrm{~N})$. Krytox, 
having a greater $\alpha$ value, yields higher $h_{\min }: 0.045 \mu \mathrm{m}(200 \mathrm{~N})$ and $0.041(600 \mathrm{~N})$. Demnum values are intermediate.

Based on a ball surface roughness of about $0.025 \mu \mathrm{m}$, initial $\lambda$ ratios (film thickness to composite surface roughness) are approximately one for Fomblin $Z$ and two for Krytox. Therefore, all tests begin in the mixed film regime $(\lambda>1)$ but as soon as any contact heating occurs, they are driven into the boundary regime $(\lambda$ ratios $<1)$.

However, the higher $\lambda$ ratio for Krytox will initially (first few meters of sliding) affect contact friction. Even though a certain amount of metal contact still exists with Krytox, the contact load supported at the actual solid contacts can be reduced because the oil film can support more load than Fomblin Z. This effective partial EHL film formation is reflected by the smoother friction traces with Krytox and a lack of initial high friction.

CONCLUSIONS--The following conclusions are drawn from the experiments:

1. Wear rates are higher in vacuum than in air.

2. Krytox exhibits the lowest wear rate in air regardless of load.

3. Krytox and Demnum both exhibit low wear rates in vacuum at high load.

4. Demnum and Fomblin $Z$ exhibit initial scuffing-like high transient friction at high load but Krytox does not.

5. Fomblin $\mathrm{Z}$ exhibits the lowest steady state friction coefficient but the highest wear rate, particularly in vacuum at high load.

6. The tribological characteristics of the three PFPE lubricants can be reasonably explained by considering both reactivity and pressure-viscosity characteristics of oils.

\section{REFERENCES}

1. P.D. Fleischauer and M.R. Hilton: "Assessment of the Tribological Requirements of Advanced Spacecraft Mechanisms," Aerospace Report No. TOR-0090(5064)-1 (1991).

2. L.S. Helmick and W.R. Jones, $\mathrm{Jr}$.: "Determination of the Thermal Stability of Perfluoroalkylethers," NASA TM-102493 (1990).

3. W.R. Jones, Jr. and K.J.L. Paciorek, T.I. Ito, and R.H. Kratzer: "Thermal Oxidative Degradation Reactions of Linear Perfluoroalkyl Ethers," Ind. Eng. Chem. Prod. Res. Dev., 22, 2 (1983) 166-170.

4. P.H. Kasai and D. Wheeler: "Degradation of Perfluoropolyethers Catalyzed by Aluminum Oxide," Applied Surface Science, 51 (1991) 201-211.

5. D.J. Carré: "The Reaction of Perfluoropolyalkylether Oil with $\mathrm{FeF}_{3}, \mathrm{AlF}_{3}$, and $\mathrm{AlCl}_{3}$ at Elevated Temperatures," ASLE Trans. 28, 1 (1985) 40-46.

6. S. Mori and W. Morales: "Tribological Reactions of Perfluoroalkyl Polyether Oils with Stainless Steel under Ultrahigh Vacuum Conditions at Room Temperature,》 Wear, 132 (1989), 111-112.

7. D.J. Carré: “The Performance of Perfluoropolyalkylethers under Boundary Conditions," Aerospace Report No. TR-0091(6945-03)-4 (1991).

8. M. Masuko, I. Fujinami, and H. Okabe: "Lubrication Performance of Perfluoropolyalkylethers under High Vacuum," Wear, 159 (1992) 249-256.

9. M. Masuko, W.R. Jones, Jr., R. Jansen, B. Ebihara, and S.V. Pepper: "A Vacuum Four-Ball Tribometer to Evaluate Liquid Lubricants for Space Applications," NASA TM in process. 


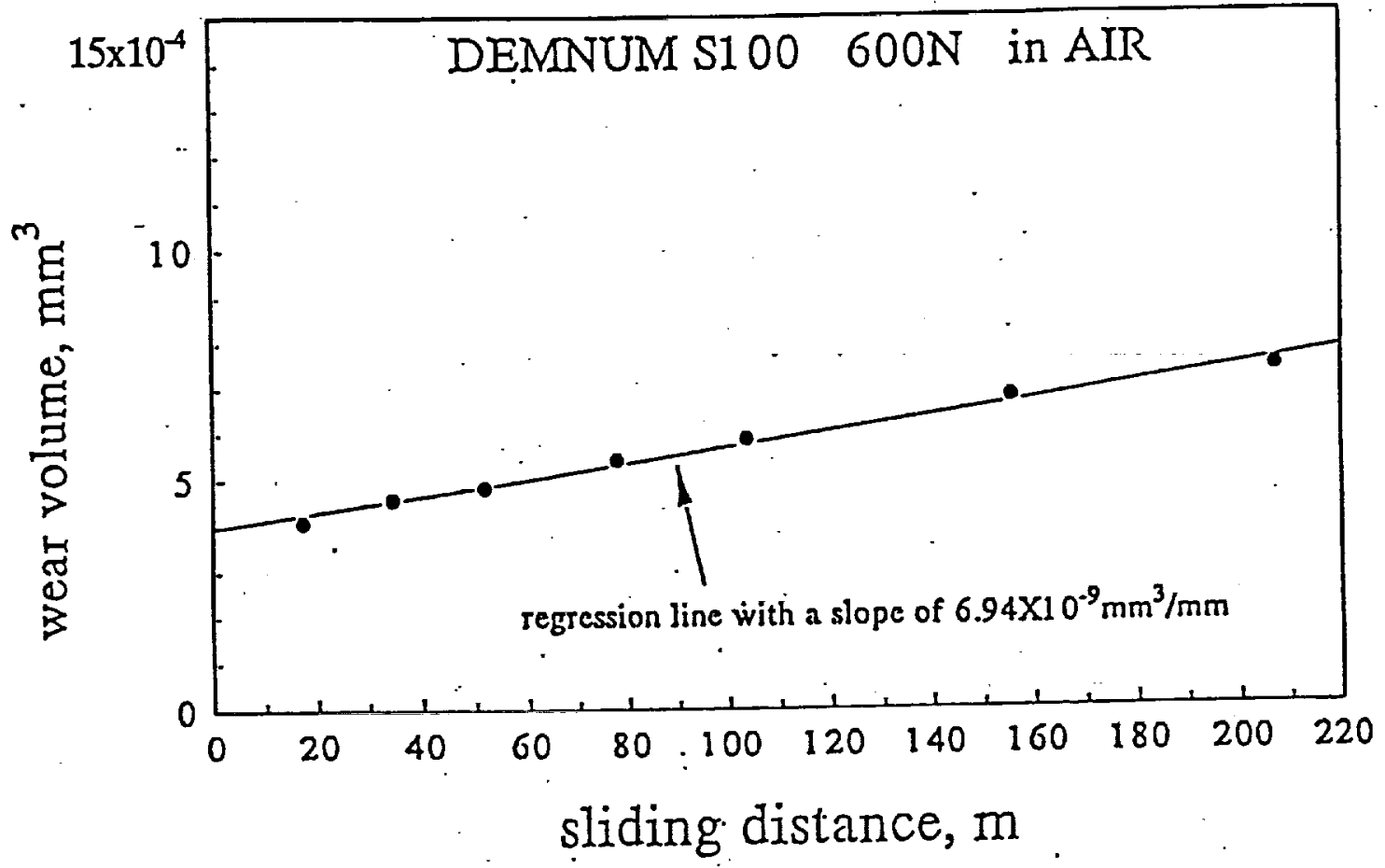

Figure 1. - Wear volume as a function of sliding distance.

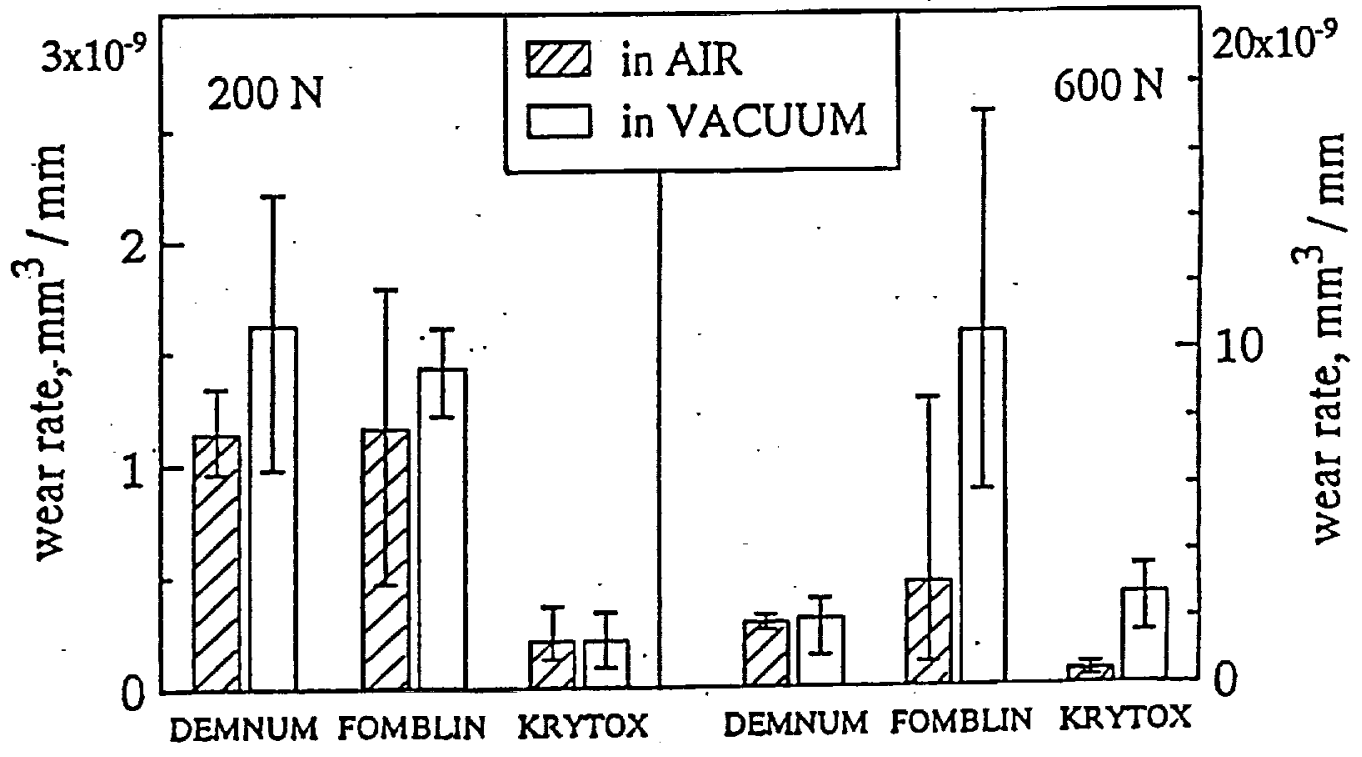

Figure 2. - Comparison of wear rates. 
Public reporting burden for this collection of information is estimated to average 1 hour per response, including the time for reviewing instructions, searching existing data sources, gathering and maintaining the data needed, and completing and reviewing the collection of information. Send comments regarding this burden estimate or any other aspect of this collection of information, including suggestions for reducing this burden, to Washington Headquarters Services, Directorate for Intormation Operations and Reports, 1215 Jeller

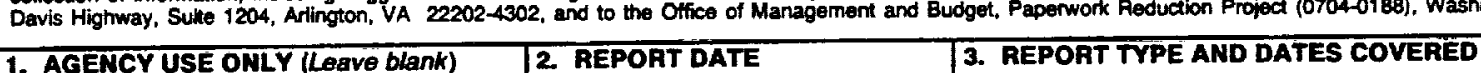

\begin{tabular}{l|l|l|} 
1. AGENCY USE ONLY (Leave blank) & $\begin{array}{c}\text { 2 REPORT DATE } \\
\text { July } 1993\end{array}$ & $\begin{array}{r}\text { 3. REPORT TYPE AND DATES COVERED } \\
\text { Technical Memorandum }\end{array}$
\end{tabular}

\section{TIIE AND SUBTTLE}

Tribological Characteristics of Perfluoropolyether Liquid Lubricants Under Sliding Conditions in High Vacuum

6. AUTHOR(S)

Masabumi Masuko, William R. Jones, Jr., and Larry S. Helmick

7. PERFORMING ORGANRATION NAME(S) AND ADDRESS(ES)

National Aeronautics and Space Administration

Lewis Research Center

Cleveland, Ohio 44135-3191

9. SPONSORINGMONTORING AGENCY NAME(S) AND ADDRESS(ES)

National Aeronautics and Space Administration

Washington, D.C. 20546-0001
5. FUNDING NUMBERS

WU-505-63-5A

8. PERFORMING ORganization REPORT NUMBER

E-7980

10. SPONSORINGMONTORING AGENCY REPORT NUHBER

NASA TM-106257

\section{SUPPLEMENTARY NOTES}

Prepared for the Eurotrib 1993 sponsored by the Hungarian Society of Mechanical Engineers, Budapest, Hungary, August 30September 2, 1993. Masabumi Masuko, Tokyo Institute of Technology, Tokyo, Japan, and William R. Jones, Jr. and Larry S. Helmick, NASA Lewis Research Center. Responsible person, William R. Jones, Jr., (216) 433-6051.

12a. DISTRIBUTON/AVALABILTY STATEMENT 12b. DISTRIBUTTON CODE

Unclassified - Unlimited

Subject Category 27

13. ABSTRACT (Max/mum 200 words)

Tribological characteristics of three PFPE's (Fomblin Z, Demnum and Krytox) were studied under high vacuum using a four-ball apparatus with $440 \mathrm{C}$ steel specimens. Fomblin $\mathrm{Z}$ and Demnum exhibited initial scuffing-like high friction whereas Krytox did not. Steady state friction with Fomblin $Z$ was the lowest among the three oils and that with Demnum and Krytox were almost the same. The lowest wear rates in air was provided by Krytox regardless of load and low wear rates in vacuum at high load were achieved with Krytox and Demnum. Results are explained by reactivity and pressure-viscosity characteristics of the oils.

\begin{tabular}{|c|c|}
\hline 14. SUBJECT TERHS \\
Perfluoropolyether; PFPE; Tribology \\
\hline $\begin{array}{c}\text { 17. SECURTY CLASSIFICATION } \\
\text { OF REPORT } \\
\text { Unclassified }\end{array}$ & $\begin{array}{c}\text { 18. SECURTY CLASSIFICATION } \\
\text { OF THIS PAGE } \\
\text { Unclassified }\end{array}$ \\
\hline
\end{tabular}

19. SECURITY CLASSIFICATION OF ABSTRACT

- Unclassified 